\section{Area Health Boards}

SIR,-I refer to the Second Report of the Subcommittee on Area Health Boards (Supplement, 27 January, p. 19). This report has not been approved by any committee of the B.M.A. except its parent, the Welsh Committee. Having been published for information and discussion, it is essential that members of the Association study this document carefully before discussing it, as it is intended it should be discussed, at divisional meetings.

Though the B.M.A. has declared itself in principle in favour of area health boards, both general practitioners and consultants have expressed the view that they would like to withhold a final decision on the merits of these boards until a pilot scheme has been produced and put into action. The scheme produced by the Welsh Committee does not represent the concept of area health boards that many doctors believe to be the best. The plan to have a number of small medical "parish councils" rather than a single board for Wales as a whole has resulted in the provision of boards too small to offer a comprehensive service to the community. No one of these tiny areas can hope to institute, staff, organize, and maintain anything like a comprehensive service; the wastage due to the duplication of administrators and committees in each small area runs completely counter to the original avowed intention of producing an area health board for Wales. Wales was chosen in the first place because it was an easily defined cohesive area of about the right size to provide an economical basis for the provision of a comprehensive service. The present plan therefore should be rejected on these grounds alone.

The report can be adversely criticized on many points, too numerous for all to be mentioned here, but its almost complete lack of any constructive suggestions regarding the hospital side of the N.H.S. is too important to be ignored. Even in the ludicrously topheavy committee system as suggested by the Welsh Committee provision is made for representation of the interests of nurses, dentists, and pharmacists, but none for hospital staff.

It is to be hoped that members discussing this report at divisional meetings will realize what a myopic view has been taken of the project of establishing an area health board and also reflect on the inability of the authors to perceive the magnitude of the opportunity offered for radical advanced planning.

If progress is to be made in this matter of planning an area health board this report must be rejected and some adequate body (Professor Miller's Planning Unit ?) be asked to do the job again.-I am, etc.,

\section{Middlesbrough. H. LeSLIE LeAming.}

\section{General Practitioners' Role in Hospital}

SIR,-Today an increasing number of hospitals depend on assistance from general practitioners. Hospitals for the mentally subnormal have employed family doctors for many years, and in these hospitals the visiting doctor has a combination of roles. Firstly, he provides a general practitioner service and relationship to the patients, especially the long-stay patients, and secondly he performs duties which would be carried out by junior hospital staff if they were appointed.

A brief analysis of work being done by general practitioners in hospitals for the mentally subnormal in this area shows the range of the work which they are doing, for example:

(1) Routine medical examination of patients on admission and subsequently, according to the custom in the hospital.

(2) General day-to-day medical care of inpatients, including the arrangement of medical treatment, but generally excluding psychiatric treatment.

(3) Emergency medical treatment of inpatients.

(4) Routine inoculation of inpatients where this is practised.

(5) Attendance at case conferences, where the practitioner can contribute to the overall assessment of the patients and the planning of the therapeutic programme.

(6) Assistance in special procedures such as electroplexy, psychological testing, and research projects.

(7) Lecturing to nursing staff on medical subjects-for instance, first aid, general medicine, anatomy, and physiology.

(8) Medical examination of hospital staff and inoculation of staff.

It is obvious that hospitals for the mentally subnormal can be grateful to their general practitioner assistants, who perform essential and comprehensive duties without which many of these hospitals could not serve the community.-I am, etc.,

$$
\begin{gathered}
\text { Westwood Hospital, } \\
\text { Bradford 6. }
\end{gathered}
$$

\section{Health Centres}

SIR,-There has been much publicity recently on the desirability of health centres (30 December 1967, p. 800), and there has been a surprising lack of B.M.A. reaction to this. The implications of section 10 of Ministry of Health circular $7 / 67$ for the future independence of general practice are highly disturbing. Consider, for example, the position of those doctors working from a health centre in the event of a dispute with a Government leading to the necessity of collective action by general practitioners. How could they be persuaded to take effective action on a resignation issue knowing that they would be left without practice premises were they to quit the N.H.S. ?

The Cumberland L.M.C., being perturbed by the whole problem of health centres, recently organized an open meeting of practitioners which was addressed by the Chairman of the Conference of L.M.C.s. Dr. R. B. L. Ridge, in lecture and discussion, covered health centres and also provision of privately financed practice premises. It emerged in the discussion that financing doctor-owned premises was not the heavy burden to the doctor that might have been expected, and that here was a viable alternative to Government-provided premises.

I would hope that other L.M.C.s would follow Cumberland's lead in holding meetings of this kind to discuss the profound medico-political implications of health centres. I would also hope that the G.M.S. Committee would be more active about beating the drum about the various financial methods by which practitioners can provide themselves with modern premises which they themselves would own and control. It seems essentiäl to own our own surgery accommodation so that we can maintain our strong bargaining position as independent contractors.-I am, etc.,

$$
\text { Cumberland. } \quad \text { A. M. RANKIN. }
$$

\section{Prescription Charges}

SIR,-With the reintroduction of prescription charges an immense amount of administrative work will arise for the appropriate authorities and for general practitioners. Doctors will have the impossible task of deciding what constitutes a chronic case, and when it begins to be chronic, and this difficulty will be increased when such patients attend with an acute condition as well. In addition the age limits will require a constant vigil of the ages of patients and will add to the already very complex load of work.

If patients exempted from paying prescription charges have to make the outlay of the charge to the pharmacist, this will present two great difficulties: the embarrassment to some in having to go to the Ministry of Social Security (still called by so many the National Assistance Board) for refund, and cases where impoverished people cannot afford the outlay.

To lessen these difficulties I suggest that a differently coloured prescription form be used in all cases where there is exemption, thereby no money being paid to the chemist. Apart from any other advantages that this would bring, it would enable a doctor to issue a coloured form for items of chronic illness and a non-coloured one for an acute illness to the same patient, and it would eliminate the embarrassment to patients of obtaining refunds.-I am, etc.,

$$
\text { Euston N.W.1. } \quad \text { M. D. RIPKA. }
$$

\section{Points from Letters}

\section{Smoking and Cancer}

Dr. Lennox Johnston (Marsascala, Malta) writes : It was announced recently that a chair of cancer research is being set up at the University of Birmingham, and that $£ 30,000$ is being made available by the British Empire Cancer Campaign to help finance this project. I read this, as I have read similar announcements, with cynicism. I am all for sensible medical research, but it seems ridiculous to go on spending large sums on cancer research before implementing the findings of previous expensive research, findings which have been repeatedly checked and which, if implemented-and they could have been over 15 years ago-would prevent vast amounts of ill-health and many thousands of early deaths annually. Implementation of the research to which I refer would be the stopping of all smoking. This would do no harm to anyone healthwise, particularly in the long run, but on the contrary would benefit the health of smokers enormously. ... It is not enough for us merely to preach-to point out the dangers of smoking. Smoking it not entirely voluntary, something in regard to which the individual can freely exercise his will. In a tobacco-addicted country like ours the psychological and pharmacological pressures on people to smoke are extremely strong. Preaching alone did not put an end to the cholera epidemic of 1850 . Only after Dr. John Snow had removed the pump handle was the epidemic ended. Similarly, we must remove the toxic drug, tobacco, from our patients ; and that, I repeat, soon and suddenly. 